\title{
Editorial
}

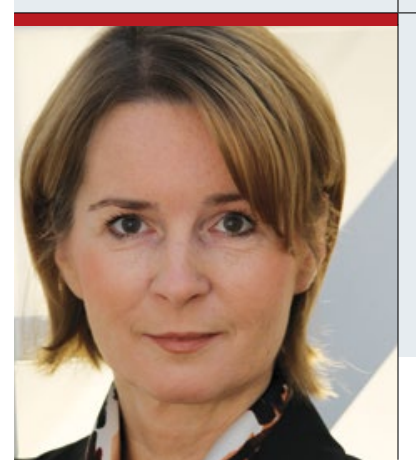

Katja Kupfer-Geißler

Chefredaktion

katja.kupfer@springer.com

facebook.com/springerpflege

\section{Hüten Sie sich vor Stürzen}

$\mathrm{M}$ anchmal dauert es ein wenig, ein Thema für das Editorial zu finden. Diesmal fiel es mir geradezu vor die Füße: ich stürzte. Es war eine blöde Situation mit einem Parkscheinautomaten auf einem extrem schmalen unebenen Bürgersteig. Während ich mich nach dem Bezahlen umdrehte und mit Geld, Sonnenbrille und dem Parkschein hantierte, dachte ich nicht mehr an die kleine Stufe. Dafür schlug ich lang hin zwischen die geparkten Autos. Nein, ich trug keine hohen Sandalen; trotzdem war der Schaden beträchtlich: neben dem ruinierten Sommeroutfit hatte ich ein paar Schürfwunden und abends einen geschwollenen Knöchel. Schlimmer aber wog, dass ich unmittelbar nach dem Sturz das Gefühl hatte, irgendwie hilflos neben mir zu stehen und doch etwas Zeit brauchte, um mich zu sammeln. Und etwas ironisch schwirrte mir die ganze Zeit der Satz "Stürze im Alter“ durch den Kopf.

Es war eine heilsame Erfahrung. Dieser Sturz aus heiterem Himmel ließ mich spüren, wie viel schlimmer er sich angefühlt hätte, wäre ich nur 20 Jahre älter gewesen - und wie viel schwerwiegender die
Folgen wohl gewesen wären? Zufällig (wer glaubt schon an Zufälle) haben wir in dieser Zeit das Thema "Sturz" auch für ein PflegeKolleg in HEILBERUFE bearbeitet. Wir haben für diese Ausgabe zwei Sportwissenschaftler gebeten, uns mit Tipps zur Senkung des Sturzrisikos zu unterstützen. Christian Kunert und Jörg Szepanski plädieren in Ihren Artikeln (ab Seite 26) für ein positives Körperkonzept, für Sport auch im hohen Alter und dafür, dass Bewegung in der Gruppe Spaß machen darf.

\section{In diesem Sinne: Viel Freude an der Fortbildung mit HEILBERUFE}

Ihre

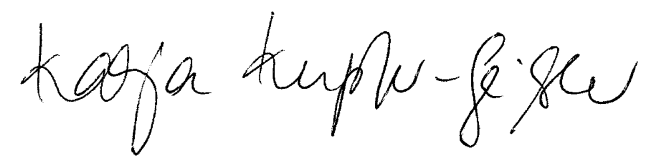

Anregungen, Wünsche, Fragen oder Lob? Scheiben Sie uns: katja.kupfer@springer.com

\section{HEILBERUFE SPEZIAL}

\section{Hygiene leben}

Hygiene - Jeder Moment zählt und: Hygiene geht jeden an! Informieren Sie sich in unserer neuen Spezial-Ausgabe in aktuellen Beiträgen über die Grundlagen, Infektionsprävention und Therapie, Recht und Gesetz.

Ob MRSA, VRE \& Co, der Umgang mit Ausbruchssituationen oder das Hygieneschutzgesetz - HEILBERUFE Spezial „Hygiene leben“ bereitet alle aktuellen Aspekte zur Hygiene für die tägliche Pflegepraxis im Krankenhaus, Pflegeheim und in der ambulanten Pflege auf.

HEILBERUFE spezial Hygiene / 9,90 Euro / ab sofort zu bestellen:

www.heilberufe.de oder heilberufe@springer.com

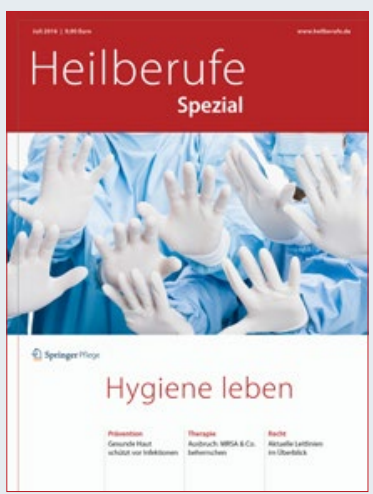

